\title{
A EMERGÊNCIA DA DOCÊNCIA NA CRECHE E JARDIM DE INFÂNCIA EM SANTA CATARINA NA PRIMEIRA METADE DO SECULO XX ${ }^{1}$
}

\author{
Rosa Batista ${ }^{2}$ \\ Leonete Luzia Schmidt ${ }^{3}$
}

\begin{abstract}
Resumo
O presente texto traz resultados da investigação sobre a emergência da docência na Educação Infantil no estado de Santa Catarina, percorrendo um conjunto de iniciativas ao longo da primeira metade do século XX - 1908 a 1949. Os principais documentos analisados foram crônicas, jornais e revistas, relatórios, certidões, históricos, decretos e regulamentos obtidos junto a arquivos do estado. Dentre eles, os arquivos do Círculo Operário e da Cia. Hering. A emergência da docência nas instituições de cuidado e de educação das crianças pequenas em Santa Catarina foi sendo forjada a partir de iniciativas de cunho religioso, filantrópico, jurídico, médico-higienista e empresarial, gestadas em diferentes contextos sociais, geográficos, culturais e políticos, com diversidade de formas de composição e organização do trabalho docente. A perspectiva médicohigiênica, advinda da puericultura, compõe a base estruturante da constituição histórica da docência na Creche. Nos Jardins de Infância, esta base estruturante se constitui a partir dos princípios da instrução, da moralização, do desenvolvimento para a civilidade, cuja constituição se dá a partir da religião, pela via da filantropia, para a construção de um "novo homem", apto para assumir a condição de trabalhador e atender ao projeto de nação que estava em curso.
\end{abstract}

Palavras-chave: História da Educação Infantil. Docência. Creche. Jardim de Infância.

\section{THE EMERGENCY TEACHING IN THE NURSERY AND KINDERGARTEN IN SANTA CATARINA IN THE FIRST HALF OF $20^{\mathrm{TH}}$ CENTURY}

\begin{abstract}
This paper brings research results about the emergence of teaching in children's education in the state of Santa Catarina, covering a number of initiatives during the first half of the twentieth century - 1908 to 1949. The main documents analyzed were chronic, newspapers and magazines, reports, certificates, historical documents, decrees, regulations, which were obtained from state archives, including the Workers' Circle and Cia. Hering arquives. The emergence of teaching in care and education institutions of young children in Santa Catarina was being forged from initiatives of religious, philanthropic, juridical, medical-hygienist and business nature, which were gestated in different social, geographical, cultural and political contexts, with diverse forms of composition and organization of teaching work. The medical-hygienic perspective, arising from child care, forms the structural basis of the teaching historical constitution in Nursery. In kindergartens, this structural base is constituted from the instruction, moralization and development to civility principles, whose constitution takes from religion, by the philanthropy way, to build a "new man", who will be able to assume the role of worker and meet the national project that was underway.
\end{abstract}

Keywords: Children's Education History. Teaching. Nursery. Kindergarten.

\footnotetext{
${ }^{1}$ Versão revista e ampliada do texto apresentado no IV Seminário de Grupos de Pesquisa sobre Crianças e Infâncias (GRUPECI), com a temática Ética e Diversidade na Pesquisa, ocorrido em setembro de 2014, na Faculdade de Educação da Universidade Federal de Goiás, em Goiânia (GO).

${ }^{2}$ Doutora em Educação. Pós-Doutoranda no Programa de Pós-Graduação em Educação da Universidade do Sul de Santa Catarina PPGE-UNISUL com pesquisa sobre A Constituição histórica da educação infantil em Santa Catarina na primeira metade do Século XX. É Pesquisadora associada ao Núcleo de Educação da pequena Infância UFSCNUPEIN. E-mail: rosab@terra.com.br

${ }^{3}$ Doutora em Educação pela PUC/SP. Professora do Programa de Pós-Graduação em Educação na Universidade do Sul de Santa Catarina - Unisul. Pesquisadora da história da educação catarinense, com foco nos anos iniciais. E-mail: leonetes@gmail.com
} 


\section{Introdução}

Este texto é resultado da pesquisa ${ }^{4}$ sobre a emergência da docência na Educação Infantil. O objetivo é analisar as configurações e dimensões da docência nas primeiras Creches e Jardins de Infância, identificadas até o momento, no estado Santa Catarina.

Buscou-se identificar as primeiras instituições de Educação Infantil do estado através do levantamento, sistematização e análise das fontes documentais que constituíram o corpus de análise, de forma a identificar os elementos constitutivos da docência neste nível de educação. Dentre elas: relatórios da Legião Brasileira de Assistência (LBA), relatórios e decretos do governo catarinense, documentos institucionais formados por atas, históricos, certidões civis, documentos privados em forma de crônicas, assim como jornais veiculados nas décadas de 1930/1940. Essas fontes constituíram-se em materiais de referência que permitiram ampliar a compreensão sobre as marcas que originaram as profissionais, e que passaram a constituir suas funções sociais como funções docentes, hoje definidas como professoras de Educação Infantil.

Algumas questões orientaram o percurso investigativo: $\mathrm{O}$ que caracterizava a docência nas primeiras Creches e Jardins de Infância? Em que contextos políticos, sociais, e econômicos emerge? Em que medida essa docência foi influenciada por bases científicas ou religiosas?

Ao percorrer as primeiras iniciativas de Jardim de Infância e Creche no estado de Santa Catarina, constatamos que:

A estruturação da força de trabalho na Educação Infantil reflete a estruturação histórica dos serviços voltados para o cuidado e a educação da criança pequena, os quais se relacionam com as tradições e as inovações socioculturais e com os modelos de organização das políticas sociais. Tais modelos estabelecem relação com as concepções do papel do Estado, da família e da sociedade na provisão de serviços de atenção à infância, no âmbito das políticas educacionais e assistenciais (VIEIRA, 2013, p. 4).

A Educação Infantil, de "forma mais acentuada que nas demais etapas da educação básica [...] constitui-se como um locus por excelência de diversidade de formas de composição e organização do trabalho docente" Colaborando para isso, entre outras questões, os processos e origens históricas das instituições de Educação Infantil e o legado das políticas de assistência social e de educação (VIEIRA, 2013, p. 5).

Essas questões foram estudadas por diferentes autores da área da educação infantil no Brasil. Dentre eles, Kramer (1982); Vieira (1986); Kishimoto (1988); Civiletti (1988); Bastos (2001); Kuhlmann Jr. (1998); Cerisara (2002); Souza (2004) e Rocha (2012). Entretanto, há um hiato no

\footnotetext{
${ }^{4}$ Estudo referente à tese de doutorado defendida no ano de 2013, na Universidade Federal de Santa Catarina -UFSC, e aprofundamento no Pós-doutorado em curso na Universidade do Sul de Santa Catarina (Unisul).
} 
que se refere à constituição histórica da docência desta etapa da educação básica, haja vista que elementos da docência atual nas instituições de Educação Infantil foram definidos nesse processo.

O conhecimento sobre o processo que marca as bases da Educação Infantil no Brasil tem permitido, de forma bastante consistente, conhecer suas origens e os contextos sociais que fizeram emergir as instituições voltadas para a criança (em Creches e Jardins de Infância), e as funções sociais que cada qual assume em seu tempo. No entanto, uma maior compreensão da construção sócio-histórica desses profissionais merece, ainda, um aprofundamento além das generalizações até aqui indicadas, que associam esta função ao gênero feminino, à maternidade e à filantropia. Como observa Kramer (2005), as atividades do magistério infantil têm sido associadas à condição feminina, ao cuidado e socialização da criança.

Os embates atuais para a definição de qual é o profissional que atuará na Educação Infantil, com quais condições de trabalho deverá atuar com as crianças e qual deve ser sua formação têm, na sua base constitutiva, uma história concreta e indícios referentes aos modos de como a docência foi sendo gestada em diferentes contextos geográficos, históricos e políticos.

Assim, as análises das origens históricas das primeiras Creches e Jardins de Infância de Santa Catarina podem contribuir para compreensão da(s) forma(s) de docência empreendida nas creches e pré-escolas neste estado, assim como, nos demais estados brasileiros.

\section{Indícios da emergência da docência na Educação Infantil em Santa Catarina}

Os registros das primeiras instituições de cuidado e educação das crianças pequenas em Santa Catarina, criadas durante a primeira metade do século XX, mostram como a docência foi sendo forjada a partir de iniciativas de cunho religioso, filantrópico, jurídico, médico-sanitário, em diferentes contextos sociais, geográficos, culturais e políticos.

No período entre 1908 e 1949 ocorreram as duas grandes guerras mundiais (1914-1918 e 1939-1945), deixando consequências na sociedade catarinense. Dentre elas, o silenciamento de uma parcela considerável da população, proibida de falar no seu idioma de origem, em função do projeto de nacionalização colocado em prática naquele período. Dentro desse contexto, os Jardins de Infância de iniciativa protestante tiveram suas atividades interrompidas ${ }^{5}$. Foi um período marcado por profunda desigualdade econômica e social, gerada pelas contingências do processo de

\footnotetext{
${ }^{5}$ Com a participação do Brasil na Primeira Guerra Mundial (1914-1918), cria-se um campo de tensão que incide sobre a população de origem alemã no estado de Santa Catarina. Sentimentos patrióticos e nacionalistas acirram conflitos e tensões entre brasileiros e alemães. Ataques contra sociedades recreativas, escolas particulares e comunitárias foram sistemáticas, promovendo sua extinção. A nacionalização torna-se um "compromisso do Estado e [...] em 1918, a partir do Decreto Federal $\mathrm{n}^{\circ}$ 13.014, possibilitou à União subvencionar as escolas primárias de populações de origem estrangeira nas zonas de imigração, com o objetivo de disseminar a língua nacional, despertar o sentimento de brasilidade [...]" (COSTA, GABARDO, FREITAS, 2005, p. 50).
} 
industrialização e urbanização que produz, ao mesmo tempo, uma elite detentora dos meios de produção e um contingente de trabalhadores e trabalhadoras suscetíveis às condições de exploração.

No bojo dessas desigualdades está o trabalho assalariado das mulheres operárias, alijadas de direitos sociais, e que, no caso específico de Santa Catarina, se efetivava prioritariamente na indústria têxtil. Nesse contexto de precárias condições de vida da classe trabalhadora, políticas assistencialistas (criação de Creches e Jardins de Infância, asilos de órfãos, ancionatos, dentre outras) ${ }^{6}$ passam a ser criadas pelo Estado e operacionalizadas por diferentes segmentos sociais, como organizações lideradas por mulheres pertencentes às elites e à igreja, que assumiam o trabalho de assistência às crianças, às mulheres e aos doentes necessitados.

Essa política assistencialista tem nos discursos científicos de cunho higienista um dos elementos constituidores da docência nas Creches e Jardins de Infância ${ }^{7}$. Em Santa Catarina, o Centro de Puericultura se destaca como veículo de disseminação de hábitos saudáveis, a partir de práticas higienizadoras e normalizadoras de condutas com foco nas crianças pequenas e nas mães operárias. Isso se revela no

[...] ideal veiculado ideologicamente pelos discursos científicos da mãe devotada ao cuidado e educação dos filhos apresenta-se como um sonho impossível face à precariedade das condições de vida e assistenciais das mulheres operárias, que se vêm obrigadas a deixar essas funções a outras mulheres. Trabalhar significa não poder zelar por seus filhos e isso implica na necessidade da criança ser educada no interior de instituições públicas por profissionais adequados/as para o efeito. É decorrente deste contexto que emerge a necessidade de uma nova profissão, as educadoras de infância, as quais vão ser consideradas, na ausência das mães, as suas substitutas mais imediatas da família (FERREIRA, 2000, p. 153).

Assim como os discursos médicos de cunho higienista, o discurso religioso também é parte da constituição histórica da docência em Santa Catarina. Os Jardins de Infância que emergem nas duas primeiras décadas do século XX, em Santa Catarina, refletem a preocupação com o cuidado e a educação das crianças numa perspectiva filantrópica, advinda dos princípios religiosos católicos e luteranos, que viam na educação dos pequenos a possibilidade de formação espiritual e moral, como estratégia para instituir e manter a cultura religiosa que promoviam. Também perspectivavam a preservação das crianças de influências externas, resguardando sua "natureza infantil", como

\footnotetext{
${ }^{6} \mathrm{Na}$ cidade de Tubarão foram criados o Colégio São José (1895) e o Hospital Nossa Senhora da Conceição (1904). Em Blumenau, é criada e inaugurada, em 30 de setembro de 1923, a maternidade Johannastift, edificada pelas Senhoras Evangélicas de Blumenau - SESB, filiada à Ordem Auxiliadora de Senhoras Evangélicas - OASE, e administrada pela Ordem das Irmãs Caritativas. Na cidade de Joinville, é criado o hospital e maternidade D. Helena. É criada também na cidade de Blumenau a Creche na Cia Hering.

${ }^{7}$ Sobre o higienismo consultar: Gondra, J. G. Homo hygienicus: educação, higiene e a reinvenção do homem. Cadernos do CEDES (UNICAMP) Campinas, v. 23, n. 59, p. 25-38, 2003. GONDRA, J. G. A sementeira do porvir: higiene e infância no século XIX. Educação e Pesquisa (USP), Educação e Pesquisa: FEUSP, v. 1, p. 99-118, 2000.
} 
também sua preparação para posterior inserção na sociedade, haja vista a urgência de uma nação “civilizada", que exigia sujeitos obedientes, saudáveis, produtivos e dóceis.

Tanto a Igreja Católica quanto a Igreja Protestante, cada qual com seus princípios, realizam suas obras assistenciais, cuja direção estava inserida no projeto de Estado em curso naquele momento. A influência das igrejas (católica e luterana) na criação dos Jardins de Infância em Santa Catarina, nos primeiros anos do século XX, mesmo que algumas ainda de forma embrionária, configura-se, também e principalmente, por uma parcela dos colonizadores vindos do continente europeu que, desde que aqui chegaram, elegeram espaços religiosos e educativos como "meios mais eficazes do combate ao que consideravam decadência cultural e religiosa" (RAMBO, 2003, p. 69).

No caso dos imigrantes luteranos, a criação dos Jardins de Infância deixava explícito que emigrar significava tão somente o rompimento com a prática de origem, mas jamais com a história de seu povo, com a sua língua ou com os seus costumes. Para os protestantes, largar a Muterland (pátria-mãe) não implicava abandonar seus costumes e suas crenças. Para os imigrantes da religião de confissão católica, entre outras determinações, estava a preservação e ampliação dos princípios cristãos da Igreja Católica Apostólica Romana.

Essas iniciativas de caráter religioso refletem um conjunto de saberes, representações, valores e atitudes em relação ao cuidado e à educação das crianças, que foram se constituindo na esteira dos conhecimentos acerca da pequena infância e dos serviços para seu atendimento, produzidos nacional e internacionalmente, que repercutiam e inspiravam as experiências educativas nos contextos das instituições de Jardim de Infância. As ideias que aqui chegaram também eram incorporações de elementos das experiências desenvolvidas em países civilizados. Nesta perspectiva, Kuhlmann (2001, p. 13) afirma:

O quadro das instituições educacionais se configura durante a segunda metade do século XIX, compondo-se de creche e do jardim- de-infância, ao lado da escola primária, do ensino profissional, da educação especial e de outras modalidades. A absorção desses modelos de civilização e progresso combinava com as referências vindas do centro de propagação europeu e norte-americano, com as peculiaridades de cada país, segundo as suas condições culturais econômicas, sociais e políticas.

A criança, compreendida como objeto de intervenção social e tutela, reclamava a necessidade da presença de um(a) profissional-educador(a) que dela se ocupasse. Tais profissionais deveriam poder atender as demandas dessa "nova" instituição, que tinha como propósito incutir nas crianças o respeito pelas leis e pela ordem social; guiá-las nos caminhos da fé e virtudes; moralizá-las e prepará-las para posterior inserção na sociedade.

\section{A emergência da docência no Jardim de Infância de Confissão Evangélica Luterana}


As experiências de Jardins de Infâncias vinculados à ordem religiosa protestante eram realizadas por mulheres dedicadas ao trabalho filantrópico, sendo este um dos seus principais objetivos, além de ser compreendido como um espaço destinado ao desenvolvimento de ideal de amor materno. Klann (2011, p. 53), em seu estudo sobre Emma Deeke, diretora e redatora no jornal Der Christenbote, na comunidade evangélica de Blumenau, refere-se a uma matéria publicada no referido jornal, de 1940, sobre "Como desenvolver uma personalidade vitoriosa":

Esta história descreve um exemplo de vida de uma menina que tinha como objetivo profissional ser uma "irmã de caridade" ou "irmã diaconisa" para continuar neste mundo a obra do Senhor. As irmãs diaconisas já existiam há algumas décadas na Alemanha e tornaram-se indispensáveis para a vida cristã no serviço de enfermagem, e também como testemunhas e "soldados" da igreja luterana. No Brasil, as comunidades evangélicas pediam para a igreja luterana na Alemanha enviarem irmãs enfermeiras para atender as necessidades de auxílio, tanto para atividades de saúde, como para os jardins de infância, para as crianças, pois a infância vivia em perigo e as crianças poderiam estar perdendo a fé cristã (KLANN, 2011, p.53).

Sobre o papel da diaconisa, o autor traz outro trecho de um artigo publicado no Der Christenbote, de setembro de 1939, em que o Pastor Raspe, supervisor das irmãs evangélicas no Brasil, descreve qual é o valor do trabalho das diaconisas para a igreja em nosso país:

Uma diaconisa, porém, é mais do que uma enfermeira, uma professora ou uma parteira. Ela é em primeiro lugar, servidora, criada, sucessora do redentor. O seu serviço é gratidão a Deus, que lhe serviu. Nas pessoas doentes ela não vê somente o homem, mas sim Deus. E o seu ordenado não é a gratidão do homem, mas sim a alegria em Deus. Demais, ela usa um traje oficial. Este traje não lhe dá somente proteção, mas sim fala de sua alta missão como representante da igreja (KLANN, 2011, p. 53).

Com relação ao papel das Sociedades de Senhoras Evangélicas na formação da mulher luterana em Blumenau, Silva (2008) informa, sobre a Escola de Economia Doméstica, que incluía culinária, administração da casa, contabilidade e cuidado com as crianças. A escola era vinculada ao pensionato evangélico de moças, que fazia parte do trabalho social de cunho educativo ${ }^{8}$ :

Na antiga moradia da família Hering, no bairro do Bom Retiro, junto à fábrica de malhas, irá se fundar uma "Frauenschule", "Escola de Mulheres", para "informar e aprimorar a educação das moças do lugar". Do seu currículo fazia parte História da Arte, Geografia, Música e Culinária e sua ênfase era no aprimoramento das virtudes domésticas, capacitando simultaneamente as jovens nas profissões que já se admitiam então para as mulheres, como a de "Hauslehrerin", "professora particular", normalmente de pintura ou de música ou de jardim-de-infância. Para ensinar as moças da burguesia blumenauense, três professoras vieram da

\footnotetext{
${ }^{8}$ De acordo com SILVA (2008, p.81), estas escolas foram criadas pelas “Associações de Senhoras”, ou Frauenverein, fundadas em Blumenau no ano de 1907. No dia 2 de setembro, a convite de Mildred Mummelthey, a "Frau Pastor", ou esposa do pastor Walter Mummelthey, reuniram-se algumas senhoras na casa pastoral com essa finalidade.
} 
Alemanha, e passaram a lecionar não apenas na "Frauenschule", mas também na "Escola Alemã" da cidade (SILVA, 2008, p. 80).

O trabalho realizado na perspectiva da formação da mulher luterana incluía a formação específica para atuar no Jardim de Infância, com a ressalva de que esta formação era direcionada para as alunas "senhoras", com destaque para o aprofundamento dos conhecimentos das áreas da educação, psicologia, metodologia e atividades práticas com o Jardim de Infância, como descrito abaixo:

Nas "Frauenschule" de Blumenau, as disciplinas educativas em geral eram comuns aos dois cursos, o da "Escola de Senhoras" e "Escola de Economia Doméstica", porém, o conteúdo da "Escola de Senhoras" era "mais aprofundado e mais extenso". Apenas às alunas "senhoras" eram ministradas as aulas de educação, psicologia e metodologia do jardim-de-infância, apoiadas por atividades práticas com os pequenos do jardim da Escola Nova e do "Johannastift". As aulas habilitavam as alunas a se tornarem professoras de jardim-da-infância, porém, de acordo com o texto do Volskskalender, seu principal objetivo não era esse, mas "ajudar à aluna no desenvolvimento primordial da sua feminilidade, da felicidade espiritual e do seu sentimento maternal" (SILVA, 2008, p. 86-87).

Nesse sentido, alinham-se o sentimento de responsabilidade sobre um serviço e/ou missão evangélica, a partir da exigência de uma habilitação para atuar nos Jardins de Infância, uma missão com intencionalidade pedagógica evidenciada no conteúdo explicitado da formação oferecida na "Escola das Senhoras". A base teórica advinda da educação, psicologia e metodologia do Jardim de Infância, mais a preocupação com a "especificidade" das práticas nesta modalidade educativa, vão configurando uma função especializada, diferente da educação realizada na família.

Muito embora, o objetivo maior estivesse entrelaçado com a formação da "feminilidade e do sentimento maternal" - pode-se inferir que a educação maternal era uma dimensão do trabalho pedagógico. Ou, como afirma Ferreira (2000, p. 182), com relação à “[...] estratégia a utilizar: a sua educação, como mãe para a maternidade e como profissional da educação de infância para a educação pública das crianças". Neste sentido, ao "definir a 'boa mãe', que é educadora, e a Educadora como profissional da educação da infância", circunscreve as funções da mulher à educação (FERREIRA, 2000, p. 182).

Outras iniciativas de Jardim de Infância, sob os preceitos da religião luterana, surgiram em Santa Catarina no período compreendido nesta pesquisa (1908-1949), instalando-se nas cidades de Joinville, Rio do Sul, Piratuba e Ipira. Constatamos que, nestes Jardins de Infância, atuavam também mulheres pertencentes à ordem religiosa protestante. O Jardim de Infância criado em 1917 em Joinville teve, como primeira professora, Clara Bornschein, que atuou de 1920 a 1924, e Dorothea Buehler - filha do Pastor Fritz Buehler, que também atuou como professora, de 1925 a 1938. Esta última era carinhosamente chamada de Tante Dolly (Tia Dolly) pelas crianças. Em se 
tratando deste Jardim de Infância, dada a dispersão de documentação e a ausência de bibliografia específica sobre o mesmo, apenas um documento foi localizado nos arquivos da Igreja Luterana da Paz, em Joinville, escrito por Dorotheia Buehler,

O documento, intitulado Histórico sobre o Jardim de Infância da Rua Jaguaruna, de 1963, apresenta uma breve história da origem desta instituição, seguida da relação das professoras e os anos em que atuaram. Neste relato, também encontramos alguns dados sobre a estrutura física do Jardim de Infância, sua localização e a entidade mantenedora: Associação Beneficente Evangélica de Joinville, que passou a ser denominada Comunidade Evangélica de Joinville.

Outro elemento importante presente no documento diz respeito às implicações causadas pelas duas guerras mundiais (1914-1918 e 1939-1945). Segundo este documento, as atividades do Jardim foram interrompidas no início da Primeira Guerra, reabrindo em janeiro de 1920 e, "por causa da nacionalização, foi novamente obrigado a cerrar as suas atividades aos 31 de março de 1938. Depois de 14 anos, foi reaberto em fevereiro de 1952" (Histórico sobre o Jardim de Infância, novembro de 1963).

$\mathrm{Na}$ continuidade das iniciativas de confissão religiosa evangélica protestante, a pesquisa de Isotton $(2004,2005)$ informa que a primeira professora do Jardim de Infância criado em Rio do Sul era Dagmar Schroeder, filha do Pastor Stoer. Em depoimento à pesquisadora, a professora afirmou que um dos pré-requisitos para atuar no Jardim de Infância era de que fosse, obrigatoriamente, evangélica, sendo o Pastor Stoer o responsável pelo trabalho de orientação pedagógica com as professoras. Este Jardim de Infância, a exemplo dos demais, tinha como papel social manter os princípios religiosos da comunidade evangélica. Pode-se afirmar que havia uma prerrogativa para assumir o trabalho junto às crianças, qual seja, um corpus de saberes no âmbito da cultura religiosa de valores morais, regras de comportamento que preparassem a criança para o futuro, que se diferenciava do âmbito privado da família.

A experiência realizada no Jardim de Infância de Piratuba e Ipira, em Santa Catarina, teve início em 1948. Hedwig Matte Werner, nascida na cidade de Ipira, sonhava ser professora. Para tanto, atuou como auxiliar no desenvolvimento das atividades de um Jardim de Infância na cidade de São Leopoldo (RS), para aprender o ofício de professora. Aos 16 anos, iniciou as atividades do Jardim de Infância como professora em Ipira e Piratuba. Embora o trabalho desenvolvido estivesse vinculado aos princípios da Ordem Auxiliadora das Senhoras Evangélicas (OASE), há nesta experiência um fator importante, que se refere à necessidade de adquirir os saberes "específicos" por meio do contato com professoras experientes e a partir do contato direto com as crianças. 


\section{A emergência da docência no Jardim de Infância de Confissão Católica}

A institucionalização do cuidado e educação das crianças pequenas em contextos de Jardim de Infância no estado de Santa Catarina também se constituiu como atividade assumida por diferentes congregações religiosas femininas, em várias cidades do estado. Entre elas: Tubarão e Florianópolis (Irmãs da Divina Providência), Canoinhas (Missionárias Filhas de Maria Auxiliadora), Criciúma (Irmãs Escolares de Nossa Senhora e Irmãs Beneditinas da Divina providência), Urussanga (Irmãs Beneditinas da Divina Providência) e Rio do Sul (Missionárias Filhas de Maria Auxiliadora).

A influência religiosa católica na área da educação, mais especificamente na educação assistencialista da família e da infância, tem suas raízes na encíclica Rerum Novarum, de autoria do Papa Leão XIII, de 1891.

A Igreja Católica - única instituição capaz de salvar a ordem social e fazer a felicidade dos povos - anunciava a sua contribuição para o controle das classes trabalhadoras. Seguindo o exemplo de outros setores, realizaram congressos católicos visando organizar e homogeneizar o clero e os leigos militantes para implementação das novas políticas assistenciais (KUHLMANN, 1998, p. 95).

Sob o tom da evangelização e da caridade, a Igreja, através de iniciativas educacionais de Jardim de Infância e Creche, buscava ampliar seu rebanho com a promessa de uma formação sólida, cristã e social dos pequenos, a fim de que viessem, no futuro, a atender a sua própria necessidade e da sociedade capitalista.

A escassez de fontes documentais acerca de algumas iniciativas e experiências de trabalho educativo realizado com as crianças limita as possibilidades de uma análise mais apurada sobre os modos como a docência foi se constituindo no âmbito dos Jardins de Infância de confissão religiosa católica. Este é o caso do Jardim de Infância criado na cidade de Tubarão, em 1908. Também sob os princípios do cristianismo católico, o Jardim de Infância criado na cidade de Canoinhas, em 1928, pelo Colégio Sagrado Coração de Jesus, e dirigido pelas Irmãs Missionárias de Maria Auxiliadora, carece de fontes documentais que permitam inferir sobre a participação direta das Irmãs na condução dos trabalhos desenvolvidos com as crianças no local.

O mesmo podemos dizer em relação ao primeiro Jardim de Infância do Colégio Coração de Jesus, na cidade de Florianópolis, cujo registro feito por Boppré (1989) ressalta dois importantes acontecimentos, no ano de 1914: a abertura do primeiro Jardim de Infância para crianças de 4 a 7 anos, e a promulgação da Lei $n^{0}$ 1.025, que autorizava a Escola Complementar Equiparada, anexa ao Colégio Coração de Jesus, a criar um ano suplementar. Em 1915, lecionavam no colégio doze professoras irmãs e uma leiga, mas não há informação sobre quem assumia o trabalho junto às crianças (BOPPRÉ, 1989). 
Os estudos de Isotton (2004) sobre o Jardim de Infância criado na cidade de Rio do Sul (1938) constatam que as Irmãs da Congregação Missionárias de Maria Auxiliadora atuavam como professoras no Jardim e nas demais séries do ensino primário. No ano de 1939, consta, nos poucos documentos encontrados, o nome da Irmã Pierina Luciani como professora.

A autora também ressalta que:

A religião, a disciplina, a formação moral, o amor à Pátria, a ênfase nos trabalhos artísticos marcara o período do jardim de infância analisado neste trabalho entre 1938-1960, atendendo aos ideais de nacionalidade impostos no Brasil e, principalmente, a busca incansável de clientela para a religião católica (ISOTTON, 2004, p. 6).

Reafirma-se, nas experiências de Jardim de Infância de confissão católica, que a formação religiosa se constituía em um dos critérios que habilitava as irmãs para atuarem nas atividades de cuidado e educação. Entretanto, as competências destas para atuarem com as crianças parece que iam além dos preceitos espirituais e morais, pois há indícios de que a formação artística, musical e científica, vinculada aos saberes relacionados às atividades cognitivas, fazia-se presentes nas atividades de Jardim de Infância.

No Sul do estado, na cidade de Criciúma, é criada em 1945 a Casa da Criança, que mais tarde passa a ser denominada Jardim de Infância Nossa Senhora Aparecida. Na cidade de Urussanga é criado o Jardim de Infância, em 1948. Essas instituições emergem num contexto de urbanização e modernização da região Sul do estado, em processo de intenso desenvolvimento e crescimento de sua economia, promovido principalmente pelo aumento da atividade de extração do carvão mineral pela Companhia Siderúrgica Nacional (CSN). Neste processo de urbanização e de industrialização, observava-se a crescente demanda pela educação e cuidado das crianças filhas de trabalhadores e trabalhadoras.

A convite do Círculo Operário São José, da Paróquia São José de Criciúma, as Irmãs Escolares de Nossa Senhora assumem a direção da Casa da Criança. O que baliza essa iniciativa, além da experiência e conhecimentos das Irmãs, são as orientações do Ministério da Educação e Saúde e do Departamento Nacional da Criança (DNCr). Este departamento faz referência ao conjunto de "qualidades indispensáveis" para o exercício do cargo pelas pessoas que trabalham com as crianças:

Todo o pessoal da Casa da Criança deve ser dotado de certas qualidades indispensáveis para o bom êxito da obra. Devotamento e simpatia pelas crianças, paciência, compreensão, e um certo preparo, sobretudo nas encarregadas da Creche, que deverão conhecer bem os princípios da Puericultura, e nas do Jardim de Infância, que deverão ter feito um curso especial desta especialidade (OLIVEIRA, 1946, p. 6). 
A abnegação, a entrega, a devoção e atitudes acolhedoras eram compreendidas como prérequisitos e definiam a profissional responsável pelo cuidado e educação das crianças pequenas. De acordo com as orientações do DNCr, para atuar na creche eram exigidos conhecimentos na área da saúde vinculados à Puericultura. Para atuação no Jardim de Infância, havia a necessidade de uma formação específica, pautada na "clássica organização pedagógica". Essa denominação é oriunda das orientações do DNCr:

A ênfase nos pré-escolares, prevendo para serem divididos em dois grupos: - os menores na Escola Materna, "onde se prepararão para o Jardim de Infância", precisavam "dormir 1 ou 2 horas durante o dia", _ os maiores no Jardim de Infância, "com sua clássica organização pedagógica, devendo ser dirigido por uma professora especializada" (OLIVEIRA 1946, p. 2).

Configurava-se, deste modo, a definição de dois profissionais com funções distintas, diferenciando, assim, o modelo de docência da Creche do modelo de docência para o Jardim de Infância. Cabe, aqui, destacar a influência das bases científicas e da Puericultura nos processos de constituição da docência, que estava diretamente vinculada às orientações médicas.

O médico é figura indispensável na Casa da Criança, ele deve ter conhecimento de pediatria e puericultura, ter pendor para tratar de crianças, e dedicar-se com solicitude e carinho à sua tarefa. As suas visitas devem ser feitas com freqüência, periodicamente, e se fôr possível mesmo todo os dias, a menos que se consiga obter uma enfermeira habilitada que o substitua, no trabalho de rotina [sic] (OLIVEIRA, 1946, p. 6).

O Jardim de Infância da Cidade de Urussanga (1948) mais tarde passa a ser denominado Casa da Criança. Posteriormente, após ampliação, recebe o nome de Paraíso da Criança. Esta iniciativa partiu do padre Agenor Neves Marques, de Ida Bez e de Olinda Bettiol, que acolheram o pedido da comunidade para criar um Jardim de Infância para seus filhos. Olinda Bettiol, primeira professora do Jardim de Infância, era leiga e contava com as "orientações pedagógicas" do padre Agenor Neves Marques e de Ida Bez para organizar e desenvolver o trabalho com as crianças.

Padre Agenor Marques Neves (1960, p. 1), em seus escritos sobre Educação Integral e Formação Cristã, definia três elementos da formação: 1- a criança que vai se formar; 2- a religião (doutrina) que vai se transmitir; 3- a Pedagogia através da metodologia educacional e da Psicologia Infantil que vai se aplicar. A pedagogia moderna, calcada nos fundamentos da Psicologia, é defendida como uma referência que perpassa essa experiência de Jardim de Infância, e que concebe a criança como "um ser individual, em metamorfose, dócil, maleável, solidária”. A natureza infantil é assim retratada nas suas palavras: "A criança, pela sua meiguice é realmente uma flor delicada e perfumosa, mas não pode ser tratada presa a um vaso, mesmo que seja do mais puro cristal. Gárrula 
e viva como é, compare-se também a um passarinho, mas não suporta isolamento nem mesmo uma gaiola de ouro" (MARQUES, 1960, p. 15).

Podemos afirmar que elementos da pedagogia froebeliana permeiam as práticas cotidianas neste Jardim de Infância, pela forte presença dos princípios religiosos. Acrescenta-se a isso a visão romântica de uma criança que se assemelha à natureza, "florzinhas do jardim que se bem cuidadas florescerão" (LIVRO DE CRÔNICAS DO PARAÍSO DA CRIANÇA, 1948-1958).

\section{A emergência da docência nas iniciativas de Creche}

As iniciativas de Creche no estado de Santa Catarina (1936-1946) partem de diversos atores sociais, com implantação da instituição por damas da sociedade (Legião Brasileira de Assistência, Sociedade de Assistência aos Lázaros e Defesa contra a Lepra), por iniciativa do Círculo Operário Católico e da classe industrial que emergia no período estudado. As diferentes formas de atendimento e as diferentes iniciativas tinham, como premissa, um conjunto de medidas que incluem a caridade, a filantropia e assistência, vinculadas às orientações médico-higiênicas.

Ressaltamos que o período em que são implantados programas assistenciais e Creches em Santa Catarina convergem para a imagem regeneradora do estado, adotada pelo então interventor federal Nereu Ramos, em conformidade com as políticas nacionais do Estado Novo empreendidas pelo governo de Getúlio Vargas. Como indica Campos (2008, p. 26): “Os discursos e práticas desse Interventor se direcionam para a institucionalização de concepções educativo-pedagógicas, religiosas, cientificistas, industriais, médico-higiênicas, assistencialistas e de urbanização".

Neste contexto, emerge na cidade de Joinville a Creche Conde Modesto Leal, uma iniciativa do Círculo Operário Católico sob a direção do padre Alberto Kolb, com a função caritativa e filantrópica coordenada pelas Irmãs de Caridade. A Igreja representada pelo $\mathrm{COCJ}^{9}$ insere-se como implementadora de ações assistenciais junto à classe operária, em apoio à consolidação das políticas públicas de caráter assistencial em âmbito nacional, a exemplo da

[...] criação de creches, que são instituições onde as mães operarias ahi deixam os seus filhinhos pela manhã, de 6 meses á 10 annos de edade, e sob os bondosos cuidados de irmãs de caridade e empregadas escolhidas e mediante uma insignificante remuneração. As criancinhas são bem alimentadas, sempre lavadas e vestidas com asseio, havendo [...] um jardim de infância com [...] instrucção e folguedos infantis. A' noitinha, de volta de seu trabalho, as mães dessas creanças levam-nas para suas casas cheias de viva satisfação, pois, já compreendem os reaes benefícios que lhes trazem e a seus filhinhos esses estabelecimentos piedosos (COCJ, Livro, 1).

\footnotetext{
${ }^{9}$ Círculo Operário Católico de Joinville.
} 
A presença das Irmãs de Caridade na condução do cuidado e educação das crianças remete para uma experiência de docência na Creche de natureza higiênica, distinta da experiência de docência no Jardim de Infância, pautada na "instrucção e folguedos infantis" (COCJ, Livro 1). Cabe destacar o projeto assistencialista que subordina as famílias ao favor e caridade pelos piedosos benefícios despendidos para garantir o corpo das crianças saudável e disciplinado e, mais que isso, que a prática higiênica fosse traduzida pelas famílias como uma conduta para além do âmbito institucional, que adentrasse os espaços privados, como forma de conservar hábitos de higiene e boa alimentação, com a intenção de produzir trabalhadores e trabalhadoras produtivos para a indústria em franco desenvolvimento.

A educação moral, cívica, patriótica e religiosa é enfatizada. Assim, indica elementos constituidores da docência no Jardim de Infância, cujo caráter se coaduna com a "grande" obra da caridade cristã, patriótica e nacionalizadora empreendida pelo então governo Getúlio Vargas e assumida pelo governador do estado Nereu Ramos. A Igreja, representada pelo Circulo Operário Católico, é coadjuvante no projeto de uma nação forte, saudável e produtiva através dos preceitos da higiene, da educação moral e espiritual, o que pode ser constatado no registro abaixo.

$\mathrm{Na}$ Capela as crianças entoarão hinos sacros, no Jardim de Infância cantarão estrofes patrióticas. Na Capela aprenderão a amar a Deus e no jardim de Infância a cultuar a Pátria. Deus e Pátria entrelaçados no mesmo Pavilhão, a surgir, vivendo unidos nos corações das nossas crianças (COCJ, Livro 2).

Na continuidade das iniciativas de caráter assistencialista no estado foi instalado, em 1943, no município de Florianópolis, o Centro de Puericultura Beatriz Ramos, sob a responsabilidade da Legião Brasileira de Assistência (LBA). De natureza médico-higiênica, previa a assistência materno-infantil e a frequência da criança na Creche, espaço reservado para os cuidados físicos e biológicos da criança sadia.

MONCORVO FILHO (s.d, p. 4), ao tecer considerações sobre a importância de um programa de proteção à infância no Brasil, propunha medidas importantes a serem materializadas no âmbito das populações empobrecidas:

[...] intensificar a assistência às mães e seus filhos, educar a população brasileira, fiscalizar e aconselhar as famílias pobres por intermédio de beneméritas e competentes visitadoras, por em prática tudo quanto de útil tem sido pela Medicina, pela Hygiene e pela Puericultura adquiridos em-prol do robustecimento da raça e do combate à nati-mortalidade e à lethalidade infantil, cuidar desveladamente da alimentação dos lactentes devem constituir as bases das melhores medidas em bem do povo.

Essa política de assistência e proteção às mães e seus filhos proclamada por Moncorvo Filho, com claras intenções de educar e fiscalizar o povo a partir dos preceitos médicos-sanitário, tem 
continuidade com as políticas do Departamento Nacional da Criança, que influenciam as políticas de assistência à infância e maternidade no estado de Santa Catarina.

É em conformidade com as orientações do DNCr e Departamento de Saúde Pública do Estado que o Centro de Puericultura Beatriz Ramos assume o propósito de atender às famílias pobres da região de Florianópolis, mais especificamente aquelas que residem nos morros, próximos ao centro da cidade. $\mathrm{O}$ atendimento às mulheres gestantes, às crianças e os serviços de creche e estagiário (este último para crianças em idade de 4 a 6 anos) estava sob a direção e orientação do clínico e pediatra Miguel de Sales Cavalcanti, médico do Departamento de Saúde Pública e especializado em misteres de puericultura. As instalações e serviços oferecidos podem ser observados no registro do relatório da LBA:

Dispensário de Higiene Pré-Natal. Cantina Maternal. Serviço Obstétrico Domiciliar. Dispensário de Odontologia. Dispensário de Higiene da Criança. Cozinha Dietética. Dispensário de fisioterapia. Serviço de Visitadora-atendentes. Serviço de Enfermagem. Creche (RELATÓRIO, LBA, 1945).

As crianças de 0 a 1 ano eram objeto de intervenção dos serviços de higiene infantil, que ficavam sob a responsabilidade de uma enfermeira e sob vigilância do puericultor e do pediatra. É neste cenário, dos centros de puericultura, que aparece a cooperação da figura da enfermeira de saúde pública nos serviços de higiene infantil: "mensageiras do bem, instruídas, disciplinadas e disciplinadoras" - a criação dos seus serviços era "uma feliz providência para o Brasil" (FIGUEIREDO, 1938, p. 69). Nas palavras do professor Carlos Chagas, na conferência realizada na Faculdade Fluminense de Medicina, em outubro de 1934, e trazida por Figueiredo, vemos sua eloquente defesa da presença da enfermeira de saúde pública e de seu papel:

Não poderei sequer esboçar, por todas as razões e sobretudo pela razão maior da incapacidade pessoal, um programa de proteção à infância; mas, de passagem, devo assinalar a alta valia que representa nas administrações sanitárias modernas e enfermeira de saúde pública, sobretudo quando aproveitado nos serviços de higiene pré-natal, infantil e escolar. Será esse o órgão de maior eficiência na proteção de nossa criança rural e dele prescindir seria grave erro de orientação técnicoadministrativa. Aproveitemos, sem demora, nessa lida de tão alto alcance social, os predicados da mulher brasileira, as doçuras de seu coração, as vantagens de seu carinho, os anseios de sua bondade infinita. Façamos enfermeiras sanitárias rurais, tantas quanto possível, o maior número que possa atingir a capacidade financeira da organização sanitária federal e das organizações estaduais, mas enfermeiras habilitadas, de alta capacidade técnica e elevado nível moral, afim de distribui-las nesse imenso território e assim proteger a criança de hoje, assim formar, vigoroso e destemido, o nosso homem do futuro (FIGUEIREDO, 1938, p. 71).

Tratando mais especificamente dos profissionais da Creche, Figueiredo (1946, p. 14) afirma que será suficiente o seguinte pessoal: um médico puericultor, uma encarregada e duas atendentes 
ou amas secas; prevendo ainda, mais à frente, no documento, que a "encarregada da creche deve ser pessoa familiarizada com a puericultura e a higiene infantil", em que o "conhecimento dos preceitos elementares da puericultura e da higiene infantil será obrigatoriamente indispensável ao exercício do cargo de encarregada da creche, a fim de assegurar a fiel execução das ordens do médico puericultor em proveito das crianças”. As qualidades indispensáveis, exigidas à encarregada e às atendentes para o "cuidado físico e mental das crianças", são que cada uma proceda de maneira "afável, bondosa, tolerante, paciente e carinhosa" (FIGUEIREDO, 1946, p. 15).

O caráter educacional evidenciado nessas iniciativas assistencialistas já foi anunciado por Kuhlmann (1998, p. 190): “[..] Há quem diga a presença da medicina na creche seria outro fator a evidenciar o seu caráter não educacional, mas é necessário compreender que o núcleo da educação dos pequenos era pensado justamente como uma educação higiênica". Reitera essa posição ao nos dizer que:

[...] no processo histórico de constituição das instituições pré-escolares destinadas à infância pobre, o assistencialismo, ele mesmo, foi configurado como uma proposta educacional específica para esse setor social, dirigida para a submissão não só das famílias, mas também das crianças das classes populares (KUHLMANN, 1999, p. $54)$.

Na esteira do processo de industrialização do país, inscreve-se a iniciativa da Creche da Cia Hering, na cidade de Blumenau, fundada em 1945, como cumprimento das exigências de proteção do trabalho feminino contidas na então recente Consolidação das Leis do Trabalho (CLT - Lei 5452/1943):

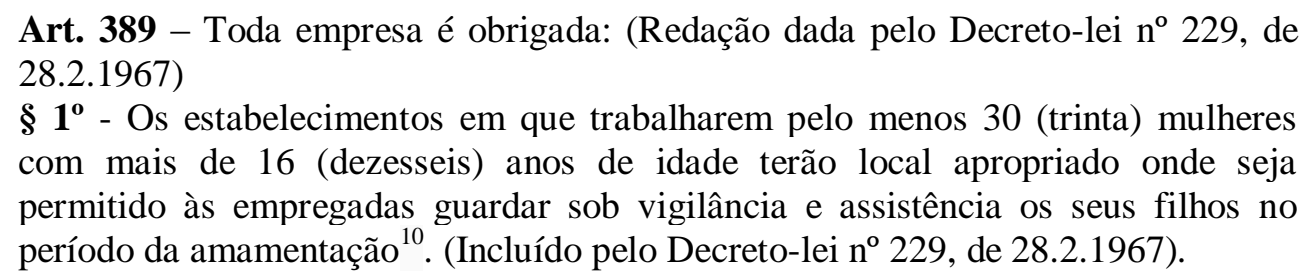

Por ser a Hering uma empresa constituída por um número expressivo de mulheres- operárias, a criação da creche aparece no estatuto da "Fundação Hermann Hering"11 como um dos "benefícios concedidos aos beneficiários provisórios ${ }^{12 \%}$.

\footnotetext{
${ }^{10} \mathrm{O}$ inciso I do Artigo $1^{\mathrm{o}}$ da Portaria do Ministério do Trabalho n. 3296/86, que dispõe sobre o reembolso-creche, institui que a obrigatoriedade da oferta de creche pode ser substituída pelo pagamento via reembolso, devendo este cobrir integralmente as despesas efetuadas com o pagamento da creche de livre escolha da empregada mãe.

${ }^{11}$ Instituída em 03/02/1935 pela Cia Hering, em homenagem ao centenário de nascimento de um dos seus fundadores, Hermann Hering.

${ }^{12}$ No que se refere ao termo "provisório", há que se esclarecer que, segundo o estatuto em questão, os beneficiários da Fundação são classificados em duas categorias, a saber: "a) - 'provisórios' - que abrangem todos os empregados e operários da Indústria Têxtil Companhia Hering, sem distinção de sexo e tempo de serviço [...]; b) - 'definitivos' que
} 
De acordo com o Estatuto e Regimento Interno da Fundação Hermann Hering (1957), o atendimento na Creche deve ser feito conforme o horário de funcionamento da indústria, sendo autorizado às mães fazerem a amamentação durante sua jornada de trabalho, atendendo aos preceitos da Consolidação das Leis Trabalhistas (CLT, 1943):

Art. 396 - Para amamentar o próprio filho, até que este complete seis (6) meses de idade, a mulher terá direito, durante a jornada de trabalho, a dois descansos especiais, de meia hora cada um.

Parágrafo único. Quando o exigir a saúde do filho, o período de seis (6) meses poderá ser dilatado, a critério da autoridade competente.

Art. 400 - Os locais destinados à guarda dos filhos das operárias durante o período da amamentação deverão possuir, no mínimo, um berçário, uma saleta da amamentação, uma cozinha dietética e uma instalação sanitária.

Essa prerrogativa jurídica exige a presença de um profissional para guardar e assistir as crianças enquanto suas mães trabalham. A enfermeira é a profissional contratada para atuar, tanto na cozinha dietética quanto nas ações de higiene e bem estar das crianças de até um ano de idade, em consonância com os indicativos do Departamento Nacional da Criança (DNCr) que, ao tratar da implantação do serviço de lactário no Distrito Federal, em 1931, definiu a função e a organização da Creche.

O atestado profissional da encarregada da creche, emitido por Dr.Abelardo Viana, chefe da Secretaria de Saúde Pública do Estado, e por Dr.Affonso Balsini, chefe da Secretaria de Higiene Infantil, evidencia o papel e as qualidades exigidas para a realização do trabalho com os bebês:

Atestamos que a Srta. Selma Bickhardt, branca, brasileira, fêz um completo estágio em nossa secção de Higiene Infantil, inclusive na cozinha dietética, estando perfeitamente apta para dirigir trabalhos de berçarios e elaborar a alimentação dos lactentes. Aos exames submetidos foi aprovada com destinção (ATESTADO, 1952, Arquivo Museu Cia Hering).

A presença dos domínios jurídico (proteção do trabalho das mulheres) e médico-sanitário (higiene infantil e saúde) na estruturação da Creche na indústria apresenta elementos que compõem as bases estruturantes dos processos de constituição histórica da docência nesse período. $\mathrm{O}$ discurso médico, ao instituir a causa da pequena infância ( 0 a 3 anos) como um campo de conhecimento, e como objeto de intervenção e observação na perspectiva dos cuidados físico e biológico, produz um conjunto de atribuições a serem realizadas por uma profissional responsável pela guarda e cuidados das crianças que correspondem aos conhecimentos e habilidades oriundos da Puericultura e Higiene Infantil. 


\section{Considerações finais}

A emergência da docência no estado de Santa Catarina ocorreu em Creches e Jardins de Infância vinculadas a congregações femininas católicas e luteranas, ao Centro de Puericultura Beatriz Ramos (LBA), à indústria têxtil (Cia. Hering) e ao Círculo Operário Católico. A docência nessas instituições foi marcada pela presença das mulheres, na sua maioria religiosas de confissão católica ou luterana. Uma docência feminina, não sem a supervisão e vigilância de padres, pastores e médicos (Puericultor e Pediatra), que figuravam como responsáveis pela direção geral dos projetos educativos das instituições. Muitas identidades das mulheres que atuavam diretamente com as crianças ficavam na obscuridade, sob denominações diversas: irmã, juvenista, tia (tante Doly) auxiliar de creche, atendente de creche, enfermeira.

As experiências de Jardins de Infância vinculados à ordem religiosa protestante eram realizadas por mulheres (denominadas professoras) dedicadas ao trabalho filantrópico, sendo este um dos seus principais objetivos, além de ser compreendido como um espaço destinado ao desenvolvimento de amor materno. Alinham-se o sentimento de responsabilidade sobre um serviço e/ou missão evangélica que configuram uma função especializada, diferente da educação realizada na família. A formação para a docência, quando havia, era pautada, principalmente, pelo desenvolvimento primordial da sua feminilidade, da felicidade espiritual e do seu sentimento maternal. A boa professora precisava desenvolver o sentimento de amor materno, o que lhe assegurava a condição para assumir essa nobre missão.

Nos Jardins de Infância vinculados à Igreja Católica, a função designada às Irmãs consistia em solidificar os princípios humanistas da Igreja, formar corpo e alma, aprender a discernir o bem do mal, o honesto do desonesto, para alcançar a felicidade neste e no outro mundo. Outra prerrogativa consistia em assistir uma suposta "infância em perigo", ou seja, aquela que não se beneficiou de todos os cuidados da criação e da educação necessárias ao projeto de industrialização. As crianças pobres eram educadas nos preceitos da missão civilizadora de preparar o cidadão do futuro, útil à pátria, seguindo a perspectiva da "polícia moral” defendida por Donzelot (1986, p. 70). Evitava-se, com isso, ao superar aqueles riscos, transformá-la em uma "infância perigosa".

Nessa perspectiva, define-se um projeto que envolve a doutrina social da Igreja e a política de Estado, em um esforço de moralização e regeneração da população empobrecida por meio de uma educação voltada para conformação social, controle e regulação dos hábitos, valores e crenças. Tanto a Igreja Católica quanto a Igreja Protestante, cada qual com seus princípios, realizam suas obras sociais de atendimento a criança pequena com a intenção de contribuir com processos de industrialização e urbanização que estão sendo gestados no estado. 
Nas iniciativas de Creche, são igualmente as mulheres (religiosas e não religiosas) que assumem o trabalho educativo, com foco na higiene e saúde do corpo das crianças, traduzindo, na prática cotidiana, a lógica médico-higiênica instituída pelo Estado. Essa política é disseminada pelo DNCr e pelo Departamento de Saúde Pública do Estado de Santa Catarina, que, por meio de subvenções, delega às instituições religiosos e às mulheres da elite (damas de caridade) a responsabilidade pela organização e administração dessas instituições.

Assim, o modelo de sociedade que está em processo de formação tem no projeto assistencialista a criança como objeto de intervenção, com claras intenções de produzir indivíduos regulados, disciplinados, asseados, educados para o enquadramento à nova configuração da sociedade. A urgência por uma nação civilizada exigia a criação de instituições e profissionais que se dedicassem à formação do futuro homem. Nesse sentido, a docência que emerge nas Creches e nos Jardins de Infância, na primeira metade do século XX, em Santa Catarina, caracteriza-se, por meio de projetos e concepções educativas de cunho assistencialista, filantrópico, religioso, entre outros, como estratégia de regulação social com vistas à racionalização da vida das mulheres e crianças.

A vinculação da Creche e Jardim de Infância às áreas da saúde e assistência social (Associação das Senhoras Evangélicas, Círculo Operário Católico, indústria, Legião Brasileira de Assistência) levou a iniciativas localizadas e a projetos educativos com elementos comuns, mas também diversos, seja em função da idade das crianças, ou da instituição, seja em função dos princípios e objetivos pedagógicos, ou ainda pelo público a que se destinava. Esse fato caracteriza o caráter não homogêneo ou linear da constituição histórica da docência nas Creches e Jardins de Infância.

Há muito para ser conhecido sobre os processos históricos de constituição da docência na Educação Infantil no estado - as práticas realizadas nas primeiras inciativas de Creches e Jardins de Infância, os processos de formação das primeiras profissionais, a tríade - gênero, religião e educação - na constituição da docência, entre outras.

Contudo, o intenso processo de busca e localização das fontes alerta para o problema de preservação da memória e dos acervos históricos sobre Educação Infantil, que carecem de espaços ou registros oficiais com os quais se possa contar e, portanto, conduzem a pensar que muitas fontes documentais podem ter se perdido. O que não permite, por outro lado, assegurar apenas a existência dessas experiências, pois outras podem ainda estar na penumbra. 


\section{Referências}

\section{Fontes Documentais}

\section{Arquivo Colégio São Bento - Criciúma (privado)}

Histórico do Colégio São Bento. Texto mimeo. Criciúma, s/d.

Livro de atas no 1 da Associação Católica Círculo São José, 1952.

Estatuto do Círculo São José de Cresciuma, (mímeo) 1935.

ARNS, Irmã Maria Helena. Histórico das Irmãs Escolares de Nossa Senhora. Colégio Sagrada Família Forquilhinha - SC. Forquilhinha: Ellus, 2000

\section{Arquivo da Paróquia da Paz - Joinville (privado)}

Histórico sobre o Jardim de Infância da Rua Jaguaruna, 1963.

\section{Arquivo do Círculo Operário de Joinville (privado)}

KOLB, Alberto. Histórico do Círculo Operário através da imprensa. Fatos e não palavras. Amparando os proletários catarinenses. Livros n. 1 [s/d]; 2 [s/d]; 3 [1941/42]; 4 [1942/46].

KOLB, Pe. Alberto. Reminiscências para a história do Círculo Operário. Livros n. 2, 4.

CÍRCULO OPERÁRIO DE JOINVILLE. Atas - livro 1, 1935.

O Boletim do Círculo Operário de Joinville. Jornal mensal da entidade.

Súmula dos Estatutos dos Círculos Operários. Princípios Básicos

\section{Arquivo Histórico da Cia. Hering - Blumenau (privado)}

FUNDAÇÃO HERMANN HERING. Estatutos e Regimento interno. 1957.

INDÚSTRIA TÊXTIL COMPANHIA HERING. Fundação Hermann Hering. Regulamento. 1947.

INDÚSTRIA TÊXTIL COMPANHIA HERING. Relatório da Diretoria e Parecer do Conselho Fiscal. Balanço Geral. Demonstração da Conta de Lucros e Perdas. Anexos e Outros Demonstrativos. Exercício Social 1944/45.

SANTA CATARINA: SECRETARIA DO INTERIOR E JUSTIÇA, EDUCAÇÃO E SAÚDE. Departamento de Saúde Pública. Atestado. 1952.

\section{Arquivo Pessoal de Ida BezBatti - Urussanga (privado)}

Certidão emitida pelo Registro Civil de Urussanga, datada de 25 de janeiro de 1958, tratando do Estatuto do Paraíso da Criança.

Livro de Crônicas do Paraíso da Criança (10/05/1948 - 30/10/1958). 
Linguagens, Educação e Sociedade, Teresina, Ano 01, n. 02, maio./ago. 2017

Revista do Programa de Pós- Graduação em Educação da UFPI| ISSN 2526-8449

MARQUES, Agenor Neves. História de Urussanga. Urussanga: Prefeitura Municipal, 1960

\section{Arquivo Público do Estado de Santa Catarina}

SANTA CATARINA. Decreto-lei n. 306, de 2 de março de 1939 - Reorganiza o Instituto de Educação. Coleção de Decretos-Leis de 1939, Florianópolis, 1939. Arquivo Público do Estado de Santa Catarina (APESC Florianópolis)

SANTA CATARINA. Relatório do Interventor Federal Nereu Ramos apresentado ao Presidente da República. Florianópolis: Imprensa Oficial, 1939 e 1943. Arquivo Público do Estado de Santa Catarina (APESC Florianópolis)

\section{Biblioteca Pública do Estado de Santa Catarina}

SANTA CATARINA. Relatório apresentado ao Dr. Otávio da Rocha Miranda, Presidente da Comissão Central da Legião Brasileira de Assistência, pelo presidente da Comissão Estadual de Santa Catarina, Dr. Ylmar Corrêa. Florianópolis: Imprensa Oficial do Estado 1948. Acesso: ABPESC, 2011

Relatório apresentado à Exma. Sra. D. Darci Samanho Vargas, DD. Presidente da Comissão Central da Legião Brasileira de Assistência, no Rio de janeiro, pela Senhora D. Beatriz Pederneira Ramos, presidente da Comissão Estadual da LBA em Santa Catarina. Florianópolis: Imprensa Oficial do Estado, 1943. Acesso: ABPESC, 2011.

. Relatório apresentado à Exma. Sra. D. Darci Samanho Vargas, DD. Presidente da Comissão Central da Legião Brasileira de Assistência, no Brasil, pela Sra. Beatriz Pederneira Ramos, presidente da Comissão Estadual da LBA em Santa Catarina.

Florianópolis, Imprensa Oficial do Estado, 1945. Acesso: ABPESC, 2011.

Relatórios da Sociedade de Assistência aos Lázaros e Defesa Contra a Lepra em Santa Catarina (1941 e 1944). Biblioteca Pública do Estado de Santa Catarina (BPESC Florianópolis)

Jornal A Notícia, Joinville, (11 jul.11 out.1942, 5 jan. 10 out. 1943). Biblioteca Pública do Estado de Santa Catarina (BPESC Florianópolis)

Jornal A Gazeta, Florianópolis, (16,11,20 jan.1940, 16, 20, 21, 26, 29, 30, 31 mar.1940, 2, 3, 5, 7, abr.1940, 12 jul.1940. 10, out.1940), Biblioteca Pública do Estado de Santa Catarina (BPESC Florianópolis)

Blog de Adalberto Day - Blumenau - http://adalbertoday.blogspot.com.br/

Fundação Carlos Chagas - http://www.fcc.org.br/pesquisa/jsp/educacaoInfancia/index.jsp

Grupo RBS - www.clicrbs.com.br

ANDRADE FILHO, Odilon de; BARROS FILHO, Sebastião; HIRTH, Maria Bernadette Pereira. Creches (Organização e Funcionamento). Rio de Janeiro: Ministério da Saúde/Departamento Nacional da Criança, 1956. (Coleção DNCr n. 151).

DEPARTAMENTO NACIONAL DA CRIANÇA (DNCr). Problemas Médico-Sociais da Infância. Rio de Janeiro: Imprensa Nacional, 1945. 
FIGUEIREDO, Gastão de. Creche. 2. ed. Rio de Janeiro: Ministério da Educação e

Saúde/Departamento Nacional da Criança - Imprensa Nacional, 1946. (Coleção D. N. Cr. n. 95).

MINISTÉRIO DA EDUCAÇÃO E SAÚDE. Departamento Nacional da Criança. Inquéritos sôbre as instituições de proteção à maternidade e à infância. Rio de Janeiro: Departamento de Imprensa Nacional, 1952. (Coleção DNCr).

MINISTÉRIO DA EDUCAÇÃO E SAÚDE. Departamento Nacional da Criança. Clube das mães da Campanha educativa. Rio de Janeiro: Departamento de Imprensa Nacional, 1960. (Coleção DNCr n. 161).

OLIVEIRA, Olinto de. A casa da criança. 3. ed. Rio de Janeiro: Ministério da Educação e Saúde/Departamento Nacional da Criança - Imprensa Nacional, 1946. (Coleção DNCr. № 72).

FIGUEIREDO, Gastão de. Como prospera o bebê (F. Briguiet). Rio de Janeiro. Ministério da Educação e Saúde/Departamento Nacional da Criança - Imprensa Nacional, 1938. Coleção DNCr

FIGUEIREDO, Gastão de. Creche. 2a . Edição. Rio de Janeiro: Ministério da Educação e Saúde/ Departamento Nacional da Criança - Imprensa Nacional, 1946. Coleção DNCr. n. 95.

Histórico da OASE - "Grupo Esperança” e Raízes da Paróquia Evangélica Luterana "Bom Pastor" - Garcia.

Jornal A NOTÍCIA, de 23/11/2011.

\section{Referências Bibliográficas}

BATISTA, Rosa. A emergência da docência na Educação Infantil no Estado de Santa Catarina: 1908-1949. Florianópolis: UFSC, 2013. 198 f. Tese (Doutorado em Educação). Universidade Federal de Santa Catarina. 2013.

BASTOS, Maria Helena Camara. Jardim de Crianças: o pioneirismo do Dr. Menezes Vieira (18751887). In: MONARCHA, Carlos (Org.). Educação da infância brasileira: (1875-1983). São Paulo: Autores Associados, 2001.

BOPPRÉ, Maria Regina. O colégio Coração de Jesus na educação catarinense (1898-1988). Florianópolis: Lunardelli, 1989.

CERISARA, Ana Beatriz. Professoras de educação infantil: entre o feminino e o profissional. SP: Cortez, 2002.

CIVILETT, Maria. V.P. A Creche e o nascimento da nova maternidade. Rio de Janeiro: ISEPP; FGV,1988.

COSTA, Andrade Iara; GABARDO, Claudia Valéria Lopes; FREITAS, Dunia Anjos de. (Org.). Tempos de Educar: Os caminhos da história do ensino na rede municipal de Joinville, SC 1851/2000. Joinville, SC: UNIVILLE, 2005.

DONZELOT, Jacques. A polícia das famílias. 3. ed. São Paulo: Graal, 2009 [1986]. 
FERREIRA, Maria Manuela. Salvar Corpos, forjar a razão: contributo para uma análise crítica da criança e da infância como construção social em Portugal: 1880-1940. Porto, PT: Instituto de Inovação Nacional, 2000.

FIGUEIREDO, Gastão de. Creche. 2. Edição. Rio de Janeiro: Ministério da Educação e Saúde/ Departamento Nacional da Criança - Imprensa Nacional, 1946. Coleção D. N. Cr. N. 95.

GONDRA, J.G. Homo hygienicus: educação, higiene e a reinvenção do homem. Cadernos do CEDES (UNICAMP), Campinas, SP, v. 23, n.59, p. 25-38, 2003.

A sementeira do porvir: higiene e infância no século XIX. Educação e Pesquisa (USP). Educação e Pesquisa: FEUSP, v. 1, p. 99-118, 2000.

HOFF, Sandino; LONGHI, Armindo José; CARDOSO, Maria Angélica. O manual didático e os quadros murais na relação educativa do Curso Normal Sagrado Coração de Jesus: 1936-1971.

Revista HISTEDBR. Campinas, SP, número especial, maio p. 128-144. 2010. Disponível em: <http://www.histedbr.fae.unicamp.br/revista/edicoes/37e/art09 37e.pdf >. Acesso em: 17 maio 2011.

ISOTTON, Andréa Patrícia Probst. A influência do luteranismo e do catolicismo nos primeiros jardins de infância em Rio do Sul. Rio do Sul: Ed. UNIDAVI, 2004.

KLANN, Carlos José. Nas páginas da História: As representações de Emma Deeke sobre o mundo da mulher protestante no Brasil (1921 - 1942). 2011. Trabalho de conclusão de curso (História). Universidade do Estado de Santa Catarina - UDESC, 2011.

KUHLMANN JUNIOR, Moysés. Infância e educação infantil: uma abordagem histórica. Porto Alegre: Mediação, 1998.

Educação infantil e currículo. In: FARIA, Ana Lucia Goulart de; PALHARES, Marina S. Educação Infantil Pós-LDB. Campinas, SP: Autores Associados, 1999. p. 51-65.

O Jardim-de-Infância e a educação das crianças pobres: final do século XIX, início do século XX. In: MONARCHA, Carlos. (Org.). Educação da infância brasileira: 1875-1983. Campinas, SP: Autores Associados, 2001. p. 3-30.

KILIPPER, Karina. As pequenas missionárias da caridade e suas práticas pedagógicas no Jardim de Infância Nossa Senhora Aparecida junto aos filhos dos operários da CSN (Siderópolis). Criciúma: UDESC, 2008. 72 f. Trabalho de Conclusão de Curso (Pedagogia) Universidade do Estado de Santa Catarina. 2008.

KISHIMOTO, TizuKo M. Os Jardins de Infância e as escolas maternais de São Paulo no início da República. Cadernos de Pesquisa, São Paulo, n. 64,1988.

KRAMER, Sônia (Org.). Profissionais de educação infantil: gestão e formação. São Paulo: Ática, 2005.

A política da pré-escola no Brasil: a arte do disfarce. Rio de Janeiro: Achiamé,1982.

MANTOVANI, Susanna; PERANI, Rita M. Uma profissão a ser inventada: o educador da primeira infância. Pro-posições, Campinas, SP, v. 10, n. 1 [28], p. 75-98, 1999. 
MARQUES, A. Neves. História de Urussanga. Urussanga: Prefeitura Municipal, 1960.

Educação Integral e Formação Cristã. Urussanga - Diocese de Tubarão: 1960 Gráfica Paraíso: Urussanga. SC

MIRANDA, Carmen Silva Meyer. Creche Conde Modesto de Leal: o legado social de padre Kolb. Joinville: Letra d'Água, 2006.

RAMBO, Arthur Blasio. O teuto-brasileiro e sua identidade. In: FIORI (Org.) Etnia e Educação: a escola "alemã" do Brasil e estudos congêneres. Florianópolis: Ed. UFSC; Tubarão: Ed. Unisul, 2003.

ROCHA, Eloisa Acires Candal. A invenção da Professora de Educação infantil. Relatório de pesquisa de estágio pós-doutoral. PPGE-PUC-RJ, 2012. (Não publicado)

SILVA, Marilda Checcucci Goçalves. Imigração, alimentação e Luteranismo em Blumenau (SC).

Caderno Espaço Feminino, v.20, n. 2, p. 75-97, ago./dez. 2008.

SOUZA, Gizele de. Instrução, o talher para o banquete da civilização: cultura escolar dos jardins-de-infância e grupos escolares no Paraná, 1900-1929. Tese (Doutorado). Programa de Estudos Pós-Graduados em Educação: História, Política, Sociedade, PUC/SP, 2004.

VIEIRA, Lívia Maria Fraga. Creches no Brasil: de mal necessário a lugar de compensar carências rumo à construção de um projeto educativo. Belo Horizonte: UFMG, 1986. Dissertação (Mestrado). Belo Horizonte: Universidade Federal de Minas Gerais - Faculdade de Educação. 1986.

$10-$ junho 2013 .

; (Coord.) Docência na Educação Infantil. Salto para o Futuro. Ano XXIII - Boletim

Recebido em: 25/12/2016

Aceito em: 25/04/2016 